\title{
O processo de humanização do ambiente hospitalar centrado no trabalhador*
}

\author{
THE HUMANIZATION PROCESS OF THE HOSPITAL ENVIRONMENT CENTERED \\ AROUND THE WORKER
}

EL PROCESO DE HUMANIZACIÓN DEL AMBIENTE HOSPITALARIO CENTRADO EN EL TRABAJADOR

\author{
Dirce Stein Backes¹, Wilson D. Lunardi Filho², Valéria Lerch Lunardi ${ }^{3}$
}

\section{RESUMO}

A humanização do ambiente hospitalar não se concretiza se estiver centrada unicamente em fatores motivacionais externos ou somente no usuário. Um programa de humanização necessita ser assumido como um processo de construção participativa que requer respeito e valorização do ser humano que cuida. Pautado em valores e princípios humanos e éticos e em idéias de Freire, este trabalho tem por objetivo explicitar como se desencadeou um processo de humanização, numa instituição hospitalar, centrado, inicialmente, no trabalhador, mediante a problematização coletiva da realidade concreta e a construção de relações dialógicas, horizontais e reflexivas. A proposta possibilitou maior compreensão do significado de humanização, com o resgate de iniciativas anteriores de humanização já adotadas, a adoção de um Banco de Idéias como um espaço para a emersão de subjetividades, a organização de ambientes coletivos acolhedores e uma maior aproximação entre a direção e trabalhadores.

\section{DESCRITORES}

Equipe de assistência ao paciente.

Inovação organizacional. Instituições de saúde (organização e administração). Trabalhadores.

\section{ABSTRACT}

The humanization of the hospital environment cannot be achieved if the focus is directed only to external motivational factors or just to the user. A humanization program needs to be assumed as a participative construction process that demands respect and valuing of the human being that provides care. Based on human and ethics values and principles and on Freire's ideas, this study aims to describe how a humanization process was unchained in a hospital, initially centering on the worker, through the collective discussion of concrete problems and the construction of horizontal, reflective dialogical relations. The proposal made possible a better comprehension of the meaning of humanization, with the rescue of previous initiatives of humanization, the elaboration of a databank in which there is room for subjectivity, the creation of warm collective areas and a closer relationship between directors and workers.

\section{KEY WORDS}

Patient care team.

Organizational innovation.

Health facilities (organization and administration).

Workers.

\section{RESUMEN}

La humanización del ambiente hospitalario no se concretiza si estuviera centrada únicamente en factores de motivación externas o solamente en el usuario. Un programa de humanización necesita ser asumido como un proceso de construcción participativa que requiere respeto y valorización del ser humano que cuida. Basados en valores y principios humanos y éticos y en ideas de Freire, este trabajo tuvo por objetivo explicitar cómo se desencadenó el proceso de humanización, en una institución hospitalaria, centrado, inicialmente, en el trabajador, mediante la problematización colectiva de la realidad concreta y la construcción de relaciones dialógicas, horizontales y reflexivas. La propuesta posibilitó mayor comprensión del significado de humanización, con el rescate de iniciativas anteriores de humanización ya adoptada, la adopción de un Banco de Ideas como un espacio para la emergencia de subjetividades, la organización de ambientes colectivos acogedores y una mayor aproximación entre la dirección y los trabajadores.

\section{DESCRIPTORES}

Equipo de asistencia al paciente. Innovación organizacional.

Instituciones de salud (organización y administración). Trabajadores.

\footnotetext{
* Texto extraído da Dissertação "A construção de um espaço dialógicoreflexivo com vistas à humanização do ambiente hospitalar", Fundação Universidade Federal do Rio Grande (FURG), 2004.

1 Enfermeira. Mestre em Enfermagem pela FURG. backesdirce@ig.com.br

2 Enfermeiro, Doutor em Enfermagem Professor Orientador/FURG lunardifilho@terra.com.br

3 Enfermeira. Doutor em Enfermagem Professora Coorientadora/ FURG vlunardi@terra.com.br
} 


\section{CONSIDERAÇÕES INICIAIS}

A organização do trabalho

pode ser vista como uma forma de maximizar as potencialidades humanas, tornando produtivos os recursos humanos, em fazer as pessoas trabalharem juntas, levando para uma tarefa comum suas potencialidades e conhecimentos individuais ${ }^{(1)}$.

Desse modo, consideramos que a humanização do ambiente hospitalar e da assistência à saúde não se concretiza se estiver centrada unicamente em fatores motivacionais externos ou somente no usuário. O hospital humanizado é aquele que contempla, em sua estrutura física, tecnológica, humana e administrativa, a valoração e o respeito à dignidade da pessoa humana, seja ela paciente, familiar ou o próprio profissional que nele trabalha, garantindo condições para um atendimento de qualidade.

Sendo o ser humano um ser de relações e não só de contatos, ele não apenas está no mundo, mas com o mundo, o que resulta de sua abertura à realidade, da problematização de sua condição na realidade do trabalho e de sua contribuição na construção desta mesma realidade ${ }^{(2-4)}$. A humanização, muito mais do que um artifício, uma técnica ou apenas uma intervenção significa estreitar relações interprofissionais, que possibilitem aos trabalhadores reconhecer a interdependência e a complementaridade de suas ações, permitindo que o coração, junto à razão, se manifeste nas relações de trabalho do dia-a-dia.

Tendo como pressuposto que a humanização da assistência emergirá com a realização pessoal e profissional dos que a fazem, desenvolver um processo de humanização, inicialmente com ênfase no trabalhador, demanda, principalmente, por parte dos dirigentes, acolhimento, escuta e uma atitude de sensibilidade, para compreender a realidade que se apresenta na perspectiva do próprio trabalhador, seja ela favorável ou não. A ênfase na pessoa humana do trabalhador, como uma das mais importantes vantagens competitivas de qualquer instituição, requer dos gestores o estímulo às iniciativas, a proximidade nas relações e a flexibilidade para compreender o ser humano em suas inquietações e perspectivas de vida. O administrador, em seu papel de dirigente, passa a exercer, no contexto da humanização, um papel de estimulador e facilitador, de alguém cuja função é concorrer para desenvolver as pessoas, suas habilidades e competências, possibilitando que sejam capazes de realizar, por si próprias, processos inovadores e, dessa forma, provocar mudanças estruturais e culturais ${ }^{(5)}$.

É preciso, assim, estimular o trabalhador a participar ativamente do processo de construção de uma proposta de humanização, ou seja, é preciso auxiliá-lo a tomar consciência da realidade, do seu estado existencial e de sua própria capacidade para transformá-la. Em outras palavras, não po- demos limitar o entendimento de um atendimento humanizado como uma prática imposta, que deveria se dar de maneira vertical e fragmentada. Diferentemente, um processo de humanização do ambiente institucional pressupõe um processo participativo e dinâmico, não excludente, baseado em relações horizontais e dialógicas ${ }^{(2-4,6-7)}$.

O profissional da saúde, ao refletir sobre as condições e relações de trabalho e o seu modo de agir, pode inserir-se na realidade, de uma maneira mais crítica e consciente. Problematizar e concretizar a humanização do ambiente, mais especificamente a partir do trabalhador, implica uma reflexão crítica e dialógica acerca dos princípios e valores que norteiam a prática dos profissionais, de modo a assumirem sua condição de sujeitos e agentes de transformação.

Logo, os profissionais de saúde, para estabelecerem um contato efetivo com os usuários, necessitam dispor de condições básicas tanto materiais como humanas para desenvolver as suas atividades, de forma digna e justa ${ }^{(8)}$. Portanto, desencadear um processo participativo para a produção de conhecimentos, em um determinado foco, supõe um jogo tático por parte do educador/coordenador $^{(2)}$ com os trabalhadores e não sobre eles e a substituição de uma maneira mais ingênua de conhecer a realidade por outra mais crítica de interligar os serviços. Produzir conhecimentos acerca da humanização nas instituições de saúde pressupõe, nesse contexto, estabelecer um processo educativo dinâmico, criativo, participativo e sistemático, a fim de que os trabalhadores assumam efetivamente $o$ seu papel de sujeitos da produção.

Assim, o trabalho objetiva explicitar como se desencadeou um processo de humanização, numa instituição hospitalar, centrado, inicialmente, no trabalhador, mediante a problematização coletiva das condições de trabalho e a construção de relações dialógicas, horizontais e reflexivas, com a tomada de consciência e de modificação de si próprio, da equipe, tendo em vista sua humanização e a humanização do meio em torno de si.

\section{TRAJETÓRIA METODOLÓGICA}

Em 2003, na Santa Casa de Misericórdia, localizada na cidade de Pelotas, no extremo Sul do Rio Grande do Sul, a partir de convite da Chefia de Enfermagem, foi constituída uma Equipe de Humanização com dezoito trabalhadores oriundos de diferentes setores do hospital, selecionados intencionalmente por suas características de liderança: enfermeiros, médicos, nutricionistas, farmacêuticos, psicólogos, assistentes sociais, contadores, administradores, economistas domésticas, dentre outros profissionais. Esta constituição objetivou, inicialmente, criar condições, em um espaço interdisciplinar, para a problematização da realidade e a reflexão dialógico-reflexiva, voltadas às condições e relações de trabalho dos profissionais. A proposta considerou, 
dentre outras, que o diálogo não pode excluir o conflito, sob pena de ser um diálogo ingênuo ${ }^{(9)}$ e que qualquer pessoa que quer expressar sua subjetividade plenamente precisa não só ter um ponto de vista claro e consistente, mas também abertura para o mundo do outro ${ }^{(10)}$.

A partir das idéias de Freire ${ }^{(2-4,6-7)}$, a criação deste espaço pressupôs o diálogo como alternativa de democratização da cultura e uma relação de unidade de contrários não-antagônicos, mas implicando uma relação horizontal de pessoa a pessoa, com centralidade no reconhecimento e valorização do potencial humano para a liberação da criatividade e liberdade na construção e transformação da realidade.

Para atender os critérios éticos, foram seguidas as recomendações da Resolução nº. 196/96, do Conselho Nacional de Saúde, bem como a solicitação de autorização ao Comitê de Ética em Pesquisa da instituição, a fim de validar a proposta de trabalho e poder divulgar as informações ${ }^{(11)}$. Assim, os participantes foram esclarecidos sobre os objetivos e a metodologia propostos, bem como assegurado o seu direito de acesso aos dados. $\mathrm{O}$ consentimento por escrito foi solicitado, com o propósito de poder utilizar as informações, garantindo que a identidade seria mantida em sigilo e assegurada à liberdade de qualquer integrante poder deixar o grupo a qualquer momento, se entendesse que seria melhor para si.

Assim, a partir da gravação e transcrição das falas dos participantes, de anotações de campo e da exploração de questões específicas, buscou-se, em um primeiro momento, desvelar o significado da humanização a fim de descobrir o núcleo de sentido que compõe uma comunicação ou que denota os valores de referência e os modelos de comportamento presentes no discurso do dia-a-dia. A seguir, procedeu-se a um resgate, no coletivo, de movimentos anteriores já desenvolvidos e vivenciados na instituição, os quais evidenciaram preocupação com a humanização institucional, com valores de respeito ao ser humano e a sua dignidade, de modo a valorizar o desencadeamento do processo de humanização proposto, a partir do próprio trabalhador, do que pensa, do que vive, do que sente e percebe.

Desse modo, mediante a análise dos múltiplos movimentos construídos a partir da equipe constituída, em busca do reconhecimento das necessidades e potencialidades dos trabalhadores como desencadeadores de um processo de humanização hospitalar, apresentamos, a seguir, o desvelamento do significado de humanização para os participantes da equipe, o resgate de iniciativas anteriores de humanização nesta instituição hospitalar e outras iniciativas implementadas, centradas, inicialmente, no trabalhador e na sua humanização.

\section{DESVELANDO O SIGNIFICADO DAHUMANIZAÇÃO}

O termo humanização suscita no ambiente hospitalar diversos entendimentos e, com eles, a multiplicidade do seu real significado. Para compreender e analisar, de forma sistematizada, o significado da humanização, optou-se, inicialmente, pela exploração das seguintes questões: 1) O que você entende por humanização? 2) No seu entender, qual deveria ser o objetivo principal da equipe de humanização? 3) De que forma, você poderia contribuir no desencadeamento do processo de humanização? A seguir, são apresentados os significados de humanização sistematizados a partir das manifestações dos constituintes da Equipe de Humanização. A fim de assegurar o anonimato dos participantes, será utilizada a Letra "E" e o número correspondente à fala, identificados no texto como [e1]; [e2]; [e3] e, assim por diante.

A humanização, no entender da Equipe de Humanização, significa, fundamentalmente, criar um clima organizacional favorável ao atendimento do paciente. É um processo que não se resume no atendimento técnico e mecânico do paciente, mas na compreensão e cuidado do paciente como um todo [e1; e3; e4]. Para que o paciente possa ser atendido de forma integral, a equipe necessita trabalhar de forma integrada e, para que uma equipe possa atuar de forma integrada, necessita melhorar a comunicação entre os profissionais [e5]; promover os trabalhadores, no sentido de valorizar iniciativas e compartilhar idéias [e7], colocando ênfase na socialização das ações humanas para estabelecer um melhor convivio [e4].

A humanização, nesse cenário, pressupõe, essencialmente, uma mudança de atitudes e comportamentos, por parte dos gestores e dos profissionais [e3]. Mesmo cientes de que todo o trabalho de humanização se dá a partir da equipe e em equipe, esses trabalhadores ainda apontam a existência de dificuldades nas relações de trabalho, na comunicação e no reconhecimento do papel efetivo de cada um dos integrantes na própria equipe. Na sua compreensão, o objetivo da equipe de humanização deveria ser, inicialmente, humanizar-se, como equipe, para humanizar o atendimento do paciente [e4]; promover a participação dos profissionais nos encontros da Equipe de Humanização [e7]; abrir um espaço para reflexões e expressão de sentimentos [e8]; contribuir com novas idéias e iniciativas [e9] e desenvolver oficinas de integração entre os profissionais [e10].

Houve manifestações explícitas do grande desejo de virem a integrar a Equipe de Humanização para, assim, auxiliála no desencadeamento da proposta, pelo entendimento de que é preciso divulgar as ações de humanização [e2]; estimular os profissionais a rever certos comportamentos nas 
relações interpessoais [e6] e contribuir com um conhecimento especifico [e11]. O comportamento refere-se à maneira de agir de um indivíduo em um momento específico, no qual reage a uma dada situação, em que outras pessoas ou objetos estão envolvidos.

Os profissionais concluíram que é possível contribuir com o processo de humanização, construindo, no coletivo, um ambiente favorável para o trabalho e que todos têm potencial para essa construção. Portanto, a humanização não deve ser de um grupo, mas de todos os envolvidos no trabalho [e12] e, para isso, urge despertar e sensibilizar o lado humano dos trabalhadores [e14].

Na verdade, ninguém humaniza ninguém. São as pessoas, através da sua inserção na realidade concreta, que propõem uma mudança, modificando-se e provocando transformações, através da reflexão, do diálogo, da escuta e da auto-sensibilização. Assim, mostra-se fundamental que os administradores de hospitais desenvolvam um estilo de administração dinâmico e aberto, capaz de criar oportunidades, liberar potencialidades, remover obstáculos, encorajar iniciativas individuais e promover o desenvolvimento pessoal e profissional, ou seja, que adotem estilos de direção democráticos e participativos, baseados nos valores humanos e sociais ${ }^{(12-13)}$.

É preciso alertar para a valorização profissional como premissa básica para o desencadeamento de qualquer processo de trabalho que se pretende humanizar, lembrando que pessoas competentes desejam trabalhar em organizações que lhes dêem retorno pela dedicação ${ }^{(14)}$, pois ninguém pode agir humanamente, se não tiver tratamento humano e reconhecido [e12]. Para isso, é preciso tornar conhecido o trabalho de humanização como sendo um espaço de transformação da cultura organizacional [e10]. Portanto, o programa de humanização de qualquer hospital ou empresa necessita reconhecer e valorizar a individualidade e singularidade de cada um dos seus trabalhadores.

Em suma, a humanização, mais do que o cumprimento de uma determinação legal, uma lei, norma e/ou medida, precisa ser e estabelecer continuamente relações horizontais. Os gestores necessitam manifestar interesse pela equipe de trabalho, conhecer seu grau de satisfação e reconhecer os reais motivos de satisfação e insatisfação pessoal e profissional. Assim, para desenvolver a humanização, o profissional demanda reconhecimento de suas necessidades e a atenção necessária para desenvolver as habilidades humanitárias ${ }^{(8)}$. Nesse sentido, a partir do desvelamento do significado da humanização, procedeu-se ao resgate de vivências anteriores dos trabalhadores participantes do grupo que lhes tivessem representado sinais de humanização.

\section{RESGATANDO SINAIS E/OU INICIATIVAS ANTERIORES DE HUMANIZAÇÃO}

A humanização do ambiente hospitalar requer, além da valorização do pensar coletivo acerca da temática, também, a valorização e reconhecimento de iniciativas anteriores, sinais, projetos e/ou programas já existentes na instituição, tendo presente um dos objetivos do Programa Nacional de Humanização - fortalecer e articular todas as iniciativas de humanização já existentes nos serviços de saúde ${ }^{(15)}$.

Portanto, o reconhecimento de iniciativas de humanização já existentes na instituição, culturalmente, favorece o desencadeamento do processo ${ }^{(6)}$. Nesse sentido, cada integrante da Equipe de Humanização foi convidado a partilhar, com os demais, os sinais de humanização já evidenciados no seu círculo de trabalho, reforçando a importância das pequenas conquistas e avanços como fatores motivacionais e de diferenciação, dentre os quais, por exemplo, o estímulo e a criatividade dos profissionais [e5] que representam algo aparentemente simples, mas de grande significação para os trabalhadores.

Por sua vez, o trabalho interdisciplinar cada vez mais integrado [e9] retrata a importância do espírito de equipe e do envolvimento de cada um e do seu saber fazer com a assistência e com os clientes ${ }^{(16)}$. Em suma, os profissionais, mais do que grandes investimentos, que geram altos custos para a instituição, valorizam relações pessoais mais próximas expressas em relações humanizadas, como um atendimento cortês e respeitoso ao telefone, momentos de confraternizações, como no final de ano, celebração de datas comemorativas, dentre outros. Para obter resultados de qualidade e relações humanas favoráveis entre os trabalhadores, é preciso que haja qualidade nas condições e no ambiente de trabalho, respeito ao ser humano, atendimento às necessidades humanas básicas, atenção às opiniões, honestidade e clareza na definição de papéis. Sendo valorizado como pessoa, o profissional reconhecerá a importância do seu desempenho não apenas para a instituição, mas também para o seu próprio crescimento e sua auto-realização. Terá condições de, como sujeito, ver, no doente, um sujeito e, através desta ótica, nortear a sua conduta profissional ${ }^{(12,17)}$.

Identificadas experiências anteriores que expressavam humanização, emergiram, no grupo, novas propostas a serem coletivamente construídas, como a criação de um banco de idéias, a partir da problematização da realidade do trabalho e da ênfase em relações dialógicas, horizontais e reflexivas, da necessidade de uma tomada de consciência e de modificação de si próprio e da equipe, tendo em vista sua humanização e a humanização do meio em torno de si.

$\begin{aligned} \text { Rev Esc Enferm USP } & \text { O processo de humanização do ambiente } \\ 2006 ; 40(2): 221-7 . & \text { hospitalar centrado no trabalhador } \\ \text { www.ee.usp.br/reeusp/ } & \text { Backes DS, Lunardi Filho WD, Lunardi VL. }\end{aligned}$




\section{O BANCO DE IDÉIAS COMO UM ESPAÇO PARAA EMERSÃO DA SUBJETIVIDADE}

A criação do Banco de Idéias ${ }^{(a)}$ foi uma iniciativa proposta pela Equipe de Humanização, com o objetivo de estimular a participação dos demais trabalhadores da instituição no processo de humanização, através da possibilidade de canalizar e expressar sugestões, idéias e questionamentos. No entanto, em vez de idéias e sugestões, o espaço foi ocupado, inicialmente, para desabafos e queixas pessoais e/ ou coletivas, ou seja, constituiu-se em um espaço de reivindicações. Contudo, manifestações dessa natureza eram, também, esperadas, pela compreensão de ser esse um processo que pressupunha rupturas pessoais internas, rompimento de barreiras setoriais e profissionais, bem como o desvendamento da cultura do silêncio, presente em muitas situações e relações no ambiente de trabalho.

As manifestações recolhidas da urna semanalmente foram detalhadas, relacionadas e, posteriormente, analisadas e discutidas nos encontros da Equipe de Humanização. Sempre que possível, o encaminhamento das sugestões, idéias e/ou reivindicações aos órgãos competentes da instituição foi imediato. Na ocorrência de manifestações nominais, as mesmas foram encaminhadas aos profissionais diretamente envolvidos, tendose como premissa que todo o programa que pressupõe um compromisso autêntico com a humanização implica um processo de dialetização dos atos de denunciar e anunciar as verdades desveladas, isto é, denunciar a estrutura desumanizante e anunciar a estrutura humanizante ${ }^{(7)}$.

Mesmo no anonimato, o Banco de Idéias representou um espaço privilegiado de trocas, vivências e reivindicações. Foi motivo, também, de crescimento pessoal e coletivo, pela possibilidade de problematizar e expressar questões latentes, provocar reflexões coletivas, além de questionar condutas ético-profissionais. Mais do que novas idéias, os trabalhadores destacaram a importância do clima favorável nas relações de trabalho, lembrando que humanizar é ter um ambiente de trabalho agradável! Que lhe valorizem! Que falem contigo como gente! É colocar o respeito sempre em primeiro lugar [e15].

O ser humano se movimenta nos espaços organizacionais, construindo oportunidades de relações e vivenciando o cuidado na ordem do seu potencial para demarcação e utilização desse espaço/direito, ou seja, de dependên-

\footnotetext{
(a) O Banco de Idéias, nada mais é, que uma URNA devidamente identificada com o nome e seus objetivos, exposta no corredor de entrada dos funcionários, próxima ao cartão ponto, no espaço reservado para as manifestações relacionadas à humanização, a fim de estimular a participação coletiva através da expressão de sugestões, idéias e questionamentos.
}

cia e interdependência ${ }^{(18)}$. Desse modo, o desvelamento de questões latentes expresso no Banco de Idéias possibilitou aos trabalhadores saírem da neutralidade e do silêncio, assumindo sua condição de sujeitos, o que representa um ato corajoso, decidido e consciente. O medo, entretanto, pode resultar de um compromisso contra a humanização, por parte dos que se dizem neutros. Assim, o verdadeiro compromisso com a humanização impele o ser humano para uma leitura cada vez mais crítica da realidade, a partir de uma nova práxis humana e ética ${ }^{(7)}$, na tentativa de construir um ambiente humanizado.

\section{AMBIENTES COLETIVOS ACOLHEDORES}

O hospital, por se tratar de um local onde os funcionários permanecem e dedicam a cada dia grande parte do seu tempo, passa a ser considerado por muitos, como a sua segunda casa/família. Logo, quanto mais aconchegantes e acolhedores os múltiplos ambientes coletivos se constituírem, tanto mais próximas poderão ser as relações afetivas e humanas.

A instituição hospitalar se constitui em um ambiente onde o ser humano trabalhador libera suas potencialidades e compartilha uma meta coletiva. Nesta, as pessoas dão algo de si mesmas e esperam algo em troca. A maneira pela qual esse espaço é moldado e estruturado influencia significativamente a qualidade de vida e a satisfação dos trabalhadores. Influencia o próprio comportamento e os objetivos pessoais de cada profissional e esse modo de ser do profissional pode afetar diretamente o modo de prestar assistência ao paciente ${ }^{(13)}$.

Entre as inúmeras manifestações proferidas pelos trabalhadores, algumas alertam que humanização significa melhorar a aparência do refeitório, do vestiário e da sala de descanso dos trabalhadores, para tornar o ambiente mais descontraído e agradável [e16] também e, ainda, humanizar significa colocar uma estante de livros na sala de descanso [e17]. A humanização assume o caráter de um ambiente de cuidado, através da capacidade de combinar o valor técnico e estrutural com o valor ético e estético, no sentido de fortalecer os laços e as qualidades humanas e melhorar a qualidade de vida ${ }^{(18)}$.

Quando o profissional compreende a sua realidade, sendo ela pessoal, ética, estética e/ou cultural, torna-se capaz de levantar hipóteses, de forma consciente, sobre o desafio dessa realidade e, desse modo, buscar soluções concretas e/ou apontar indicativos de mudança ${ }^{(2)}$. A conscientização resulta, nesse contexto, em inserção crítica na história, na realidade concreta, no sentido de que sempre mais assuma o papel de sujeito na construção de mudanças estruturais e culturais. 
Convivemos, com freqüência, em ambientes tensos e pouco humanizados, cujo funcionamento pode ser quase perfeito quanto à técnica, porém desprovidos de afeto, atenção e solidariedade ${ }^{(17)}$. Para tornar o clima de trabalho mais prazeroso e mais humano, é fundamental estimular e atentar para atos significativos, isto é, de descontração e integração manifestados pelos trabalhadores, como forma de resgatar a sua subjetividade e minimizar as relações de estresse e tensão.

A humanização possibilita ao ser humano exercer suas potencialidades criativas, desde que as condições ambientais e profissionais sejam facilitadoras ${ }^{(19)}$. A humanização significa conciliar o trabalho com a vida pessoal e a felicidade coletiva. Humanizar significa, ainda, ser capaz de identificar e valorizar, na prática, o que é importante e fundamental aos olhos de quem convive e estabelece as relações de trabalho no coletivo, como ter sua condição de sujeito trabalhador reconhecida.

\section{MAIOR APROXIMAÇÃO ENTRE DIREÇÃO E TRABALHADORES}

Ser lembrado, ouvido, valorizado e reconhecido pelos gestores representa, para a Equipe de Humanização, um dos fatores mais satisfatórios, em termos de humanização, pois, em suma, humanização é ser reconhecido e ouvido pela administração [e4], ou seja, humanização é a administração estar próxima dos funcionários, para conhecer as suas angústias e necessidades [e18]. Estas, entre outras, foram algumas das manifestações mencionadas em relação à administração. Assim, não basta, no entender dos profissionais, ser trabalhador na instituição; importa sim, participar efetivamente do seu processo de desenvolvimento, ser reconhecido, ouvido e respeitado, a partir de sua leitura da realidade.

Ser ouvido representa, nesse processo, algo que ultrapassa a possibilidade auditiva de cada um. Escutar significa, por parte dos dirigentes, a disponibilidade permanente em ouvir e acolher a expressão de anseios, expectativas e angústias dos trabalhadores. A verdadeira escuta, ou seja, a prática democrática de escutar, confere o direito de discordar, de contrapor idéias e de se posicionar como sujeito do processo ${ }^{(2)}$.

Estabelecer relações humanas próximas entre gestores e trabalhadores significa realizar uma leitura reflexiva da parcela de mundo que tem significação para os trabalhadores. Respeitar a leitura de mundo dos trabalhadores, portanto, pressupõe um diálogo horizontal e uma atitude de humildade crítica, por parte dos dirigentes, o que

exprime uma das raras certezas de que ninguém é superior a ninguém, assim como a falta de humildade se expressa na arrogância e na falsa superioridade de uma pessoa sobre a outra, o que representa uma transgressão da vocação humana do ser mais ${ }^{(2)}$.
Um número incalculável de ressentimentos, frustrações e descontentamentos, de atitudes de oposição e descomprometimento ocorre, muitas vezes,

porque os profissionais são colocados à beira da estrada, porque não são chamados a participar do equacionamento de problemas que, direta ou indiretamente, Ihes dizem respeito ${ }^{(20)}$

Nessa perspectiva, quanto mais os trabalhadores se afirmarem como sujeitos ativos e dinâmicos nas relações com os seus superiores tanto melhor irão desenvolver as suas aptidões, em favor do crescimento e desenvolvimento pessoal e institucional. O trabalhador valorizado profissionalmente pode articular e harmonizar seu ambiente de trabalho e produzir o máximo de rendimento, com prazer e realização.

A manifestação relacionada à necessidade de proximidade entre gestores e trabalhadores pressupõe, no contexto da humanização, a valorização da vida, acima de qualquer processo estrutural e/ou técnico-científico. São os profissionais, através do seu trabalho e das relações que estabelecem, que determinam e retratam se o atendimento ao usuário é ou não é humanizado. Todo processo de humanização, para ser efetivo e transformador, necessita estreitar os laços de comunicação, na tentativa de desvendar e respeitar a leitura de mundo dos trabalhadores, favorecendo a compreensão contínua da realidade.

\section{CONSIDERAÇÕES FINAIS}

Desencadear um processo de humanização, no âmbito hospitalar, não resulta de uma percepção isolada, mas constitui uma síntese de muitas percepções, vivências e intervenções pautadas em valores e princípios humanos e éticos. Resulta, sobretudo, do encontro com a realidade concreta, com quem a constitui, pacientes, familiares, trabalhadores, administração, num vai-e-vem incessante de novas descobertas, questionamentos e respostas para as necessidades emergentes. Processo, portanto, que permite construir e/ou desconstruir representações recebidas da sociedade ou da educação. Assim, este trabalho teve como objetivo explicitar como se desencadeou um processo de humanização, numa instituição hospitalar, centrando-o, inicialmente, na humanização do trabalhador.

Oportunizar ao trabalhador a expressão e participação nesse processo, de forma comprometida, foi de fundamental importância para o desvelamento do significado da humanização, o que implica no surgimento mento de um clima organizacional favorável à humanização, pautado pela horizontalidade, pela construção de espaços dialógicos-reflexivos, com possibilidades de mudanças nos gestores e nos profissionais.

O próprio processo de desvendamento da proposta infundiu, nos integrantes da Equipe de Humanização, o colo- 
car-se em uma atitude ativa de participação, já que quanto mais adentramos a realidade histórico-social, tanto mais nos tornamos comprometidos com a mudança, isto é, com a humanização institucional. Assim, se deu o resgate de iniciativas prévias de humanização vivenciadas, como de motivação para o trabalho, de integração no trabalho em equipe, com a proposição de novas iniciativas, como um banco de idéias, ambientes coletivos mais acolhedores e o reconhecimento do trabalhador como sujeito, mediante maior aproximação com a direção institucional.

\section{REFERÊNCIAS}

(1) Lunardi Filho WD. Divisão do trabalho: trabalhador especializado, trabalho (des)qualificado? Sinergia. 1995;7(2):10-80.

(2) Freire P. Educação como prática da liberdade. $22^{a}$ ed. Rio de janeiro: Paz e Terra; 1996.

(3) Freire P. Ação cultural para a liberdade. $6^{\mathrm{a}}$ ed. Rio de Janeiro: Paz e Terra; 1982.

(4) Freire P. Pedagogia da autonomia: saber necessário à prática educativa. Rio de Janeiro: Paz e Terra; 1993.

(5) Caravantes GR. A administração e qualidade: a superação dos desafios. São Paulo: Makron Books; 1997.

(6) Freire P. Pedagogia do oprimido. $17^{\mathrm{a}}$ ed. Rio de Janeiro: Paz e Terra; 1987.

(7) Freire P. Conscientização: teoria e prática da libertação. $3^{a}$ ed. São Paulo: Morais; 1980.

(8) Selli L. Reflexão sobre o atendimento profissional humanizado. Mundo Saúde. 2003;27(2):248-53.

(9) Gadotti M. Educação e mudança. Rio de Janeiro: Paz e Terra; 1979.

(10) Bennis W. A formação do líder. São Paulo: Atlas; 1996.

(11) Brasil. Conselho Nacional de Saúde. Resolução 196/96, de 10 de outubro. Dispõe sobre diretrizes e normas regulamentares de pesquisa envolvendo seres humanos. Brasília: O Conselho; 1996.
Para os profissionais, o programa de humanização parece constituir-se na oportunidade de resgatar o verdadeiro sentido de sua prática, o valor do seu trabalho e do trabalhar em equipe e a busca pelo aprimoramento das relações que estabelecem entre si, com os usuários, com a administração, bem como do hospital com a comunidade, de modo que seja valorizada a dimensão humana e subjetiva dos sujeitos envolvidos.

(12) Mendes IC. Enfoque humanístico à comunicação em enfermagem. São Paulo: Sarvier; 1994.

(13) Chiavenato I. Gerenciando pessoas. O passo decisivo para a administração participativa. São Paulo: Makron Books; 1992.

(14) Shinyahiki R. Os donos do futuro. São Paulo: Infinito; 2000.

(15) Pessini L. Humanização em saúde: o resgate do ser com competência científica. Mundo Saúde. 2003;27(2):203-5.

(16) Hoga LAK. A dimensão subjetiva do profissional na humanização da assistência à saúde: uma reflexão. Rev Esc Enferm USP. 2004;38(1):13-20.

(17) Nogueira LCL. Gerenciamento pela Qualidade Total na Saúde. $2^{\mathrm{a}}$ ed. Belo Horizonte: Desenvolvimento Gerencial; 1999.

(18) Bettinelli LA, Waskievicz J, Erdamnn AL. Humanização do cuidado no ambiente hospitalar. In: Pessini L, Bertachini L, organizadores. Humanização e cuidados paliativos. São Paulo: Loyola; 2004. p. 87-99.

(19) Kanaane R. Comportamento humano nas organizações: o homem rumo ao século XXI. São Paulo: Atlas; 1995.

(20) Chiappin A. Psicologia das relações humanas no hospital. Porto Alegre: Globo; 1998. 